\title{
The Journal of Youth and Adolescence at 50: Completing the Move Toward a Curator Model of Editing
}

\author{
Roger J. R. Levesque ${ }^{1}$
}

Received: 16 November 2020 / Accepted: 16 November 2020 / Published online: 26 November 2020

(c) Springer Science+Business Media, LLC, part of Springer Nature 2020

\section{Introduction}

A decade ago, an editorial highlighted how the journal reflected a matured study of adolescence and was leaving a strong intellectual footprint (see Levesque 2011a). Before that anniversary, the journal had been shifting its mission. The journal had narrowed its focus to quantitative research that vigorously tested data. It had taken many years to reach the end of that shift, but it was squarely settled in the journal's mission by the beginning of its 4 th decade. This editorial examines the model of editing that supports the shift and some of its outcomes as the journal enters its fifth decade.

\section{Outcomes of a Narrowed Mission}

The most notable outcome of the journal's narrowed mission has been efforts to increase the scientific rigor of manuscripts pursued for publication. Fundamentally, this initiative would not have happened without incredible support from literally thousands of talented researchers willing to contribute to the field's development. All that really needed to be done was follow their lead. Doing so involved revisiting and explicitly stating expectations about statistical analyses and encouraging the use of sensitivity analyses (Levesque 2015). It also included a concerted effort to increase transparency and replicability, as reflected in publishing statements publicly declaring each author's contributions (Levesque 2012) and addressing the availability of raw data (Levesque 2017). These efforts also included reaching out to authors before they would even

Roger J. R. Levesque

rlevesqu@indiana.edu

1 Indiana University, 302 Sycamore Hall, Bloomington, IN 47405, USA submit (or even begin the hard work of moving findings to publishable form). To give authors a better sense of acceptable manuscripts, increased information was provided to prospective authors so they could better understand the journal's expectations (Levesque 2007a, 2019a). These initiatives were meant to work in tandem, but some were much more successful than others. Not surprisingly, the more successful ones are reflected in the articles published in the journal, as those have hewed most closely to initiatives meant to develop the most rigorous and impactful contributions to developmental science.

Another expected outcome of the journal's shifting mission was increased rejection rates. Given this expectation, efforts were made to mitigate the impact of the shift on researchers and the field. Two examples are illustrative. First, the move toward focusing on quantitative work meant that there were no clear adolescent-focused outlets for non-empirical reviews of the literature and for manuscripts developing measures. Recognition of the importance of such work resulted in launching the Adolescent Research Review (see Levesque 2016a, 2016b). Second, the narrowed mission meant increasing the rejection of manuscripts from emerging scholars. This led to redoubling efforts to engage emerging scholars. As a result, since the beginning of the journal's 4th decade and for every volume since (see Levesque 2011b), and with the generous financial support of the publisher, the journal has selected a recipient for its Emerging Scholar Best Article Award (see, e.g., Levesque 2018a, 2019b, 2020). In addition, emerging scholars have been increasingly involved in peer review. Identifying and encouraging the development of scholars continues to be a priority, as are efforts to provide a suite of outlets for them, including the Adolescent Research Review (see Levesque 2016a), a major works reference (Levesque 2011c, 2018b), and an active book series (see, e.g., Levesque 2019c). These efforts were all in the works well before the past decade, and are a testament to the publishers' foresight and understanding of emerging needs, particularly as exemplified by 
Judy Jones who was instrumental in shepherding these projects to fruition.

\section{Advancing the Curator Model of Editing}

The above developments reveal much more than efforts to develop, support, and shape what the study of adolescence produces; they reveal the result of a deliberate effort to advance a specific model of editing. The journal uses a curator model that typically develops articles to fit its mission, both in terms of substance and style. That model is but one of many supporting scientific publishing. In fact, several other models are gaining much attention. For example, the move toward open science has nudged some toward focusing more on methodological/statistical analyses and letting the market of ideas determine their worth. Some focus on reducing narratives and publishing the shortest articles possible, with the belief that data and analyses should speak for themselves. Some choose to ignore theory or the quality of the research base leading to current studies. Some shun the use of traditional peer review. As these models gain traction and reduce the role of publishers and editors, they move the field away from a curator model that grounds this journal.

The curator model of editing is simple to understand. Generally, curators sift through content in a particular topic area, pull out materials they deem most valuable for people interested in that topic, and eliminate less useful items. They identify, keep and develop the most valid, reliable, robust, useful and relevant research. This involves testing technical effectiveness and evaluating the fundamental utility of a study's content. It includes trying to make sense of that content, which can involve sorting, organizing, and structuring manuscripts in more accessible ways. It also means having authors craft their narratives in ways that comport with the journal's style of presenting information so that studies essentially follow and further the journal's brand. At its core, for each submission, this approach brings together teams of researchers who seek to bring out a study's underlying value and its place in a particular area of research and the journal's mission. Curator editors help others make sense to others.

Editors and reviewers who adopt a curating model essentially do what successful academic authors do. They have a passion for a particular discipline and devote their lives to understanding it. Like authors, curators spend time researching, writing, and thinking about a particular study. Their role is not simply to give a thumbs up or down for an editorial decision. Instead, curating editors identify and work with reviewers who can help authors develop their studies into the most effective manuscripts possible; and they spend substantial energy considering reviews and thinking about manuscripts deemed worth pursuing for publication in their journal. Effective curator editors and reviewers essentially operate the way they want authors to operate. They want authors to become good curators of their own work. They understand the flood of new content available in research and the need to make sense of that research in ways that readers will understand the need for a study to fill a research gap worth addressing. They share the common goal of helping readers sort out content in meaningful ways. Curating editors and reviewers help authors become more effective curators of their own work.

The curator model requires considerable investment from editors and editorial boards. Their investment is not entirely unproblematic. It necessarily comes at the cost of their own research productivity, especially the productivity of necessarily highly research active scholars who temporarily put aside their own work in their service to others. While some reviewers may benefit from getting a sense of what is happening in a particular field, the reality is that anonymously reviewing other people's work requires a large dose of selfless generosity that modern academics does not reward.

The curator model may require considerable generous spirit from those working with manuscripts, but that generosity may not be perceived as such from its recipients. The curator model rests on developing manuscripts and often is misunderstood. It most often has been criticized for relying too heavily on reviewers or the whims of the lead editor. It also has been criticized for being too demanding and too concerned with what some deem minor technicalities and details better left ignored. Several authors openly resist it. Some authors are more subtle and rebuke requested changes through edits at proof stage, all in hopes that it will be too late for editors to notice (it is not).

There clearly is much give and take between curating editors and authors, and it is to everyone's benefit. As much as it is true that only the authors' names appear on their articles and that it is their work, it also is true that their articles receive the journal's imprimatur, something that authors seek and editors guard closely. This may seem to set up a necessarily adversarial relationship as authors want to produce their work while editors ask them to consider the journal's mission. But the relationship fundamentally is one of shared goals.

As the journal continues to work within a curator model, it is important to acknowledge and be grateful for the literally thousands of reviewers who curate and the authors who trust it. This editorial is being written in the middle of 2020, when already over 1000 initial submissions have been received. Manuscripts that make it out for full external review are reviewed, on average, by at least three reviewers. Some are reviewed by more when they span multiple areas of expertise. Some reviews purposefully include solid 
researchers who are not experts in a manuscript's topic, which helps to support the journal's broad, multidisciplinary reach. Considering a manuscript seriously enough to send it out for review means significant commitment to it. That commitment means that the time and energy of numerous outstanding researchers in our field will turn their attention to that work. Day in and day out, it is just astonishing (and incredibly heartening) to have outstanding researchers so selflessly share their talents and expertise (see, e.g., Levesque 2007b, 2009, 2013, 2019d).

\section{Conclusion}

The Journal of Youth and Adolescence marks its $50^{\text {th }}$ year with this issue. That is quite an accomplishment. It is especially so given the journal's narrowed mission and curator model of editing. The journal relies on the remarkable generosity of board members and others willing to assist. They do so without any public credit, even though they are instrumental in publishing articles. Systems that rely on altruism are somewhat out of the ordinary, particularly in this academic environment. Yet, if the past decade reveals anything, it is a proof of concept even in these rapidly changing times. The past decade, indeed the past half century, reveals a need for an outlet devoted to developing manuscripts. Of course, the journal is not unique in this regard. Hopefully, journals that embrace the model confirm the need for journals that support authors' efforts to develop their best scholarship, one that benefits from a broad community of dedicated scholars who respond to that need.

\section{Compliance with Ethical Standards}

Conflict of Interest The author is the editor of the Journal of Youth and Adolescence.

Publisher's note Springer Nature remains neutral with regard to jurisdictional claims in published maps and institutional affiliations.

\section{References}

Levesque, R. J. R. (2020). Anna Vannucii receives emerging scholar best article award, 2020. Journal of Youth and Adolescence, 49, 2407-2408.

Levesque, R. J. R. (2019a). Presubmission inquiries: problematic, counterproductive, and unnecessary. Journal of Youth and Adolescence, 48, 651-654.

Levesque, R. J. R. (2019b). Emerging scholar best article award, 2019. Journal of Youth and Adolescence, 48, 2331-2332.

Levesque, R. J. R. (2019c). Adolescents and constitutional law: regulating social contexts of development. New York, NY: Springer Nature Publishers.

Levesque, R. J. R. (2019d). In memoriam: David B. Estell. Journal of Youth and Adolescence, 48, 1243-1244.

Levesque, R. J. R. (2018a). Emerging scholar best article award, 2018. Journal of Youth and Adolescence, 47, 2637-2638.

Levesque, R. J. R. (Ed.) (2018b). The encyclopedia of adolescence. 2nd edn. New York, NY: SpringerNature Publishers.

Levesque, R. J. R. (2017). Data sharing mandates, developmental science, and responsibly supporting authors. Journal of Youth and Adolescence, 46, 2401-2406.

Levesque, R. J. (2016b). Reviews in research on adolescence: genres, trends, and challenges. Adolescent Research Review, 1(1), 3-13.

Levesque, R. J. (2016a). The editor's inaugural introduction. Adolescent Research Review, 1(1), 1-2.

Levesque, R. J. R. (2015). Statistical guidelines for publishing in the Journal of Youth and Adolescence. Journal of Youth and Adolescence, 44, 2391-2394.

Levesque, R. J. R. (2013). In memoriam: Daniel Offer, 1929-2013. Journal of Youth and Adolescence, 42, 1497.

Levesque, R. J. R. (2012). Authorships, collaborations, and acknowledgments: on the increasing responsibility to report relative contributions. Journal of Youth and Adolescence, 41, 1685-1687.

Levesque, R. J. R. (2011a). The Journal of Youth and Adolescence at 40. Journal of Youth and Adolescence, 40, 1-2.

Levesque, R. J. R. (2011b). Emerging scholar best article award, 2011. Journal of Youth and Adolescence, 40, 1565-1567.

Levesque, R. J. R. (Ed.) (2011c). The encyclopedia of adolescence. 1st edn. New York, NY: Springer Publishers.

Levesque, R. J. R. (2009). In memoriam: Xiaojia Ge, 1954-2009. Journal of Youth and Adolescence, 38, 1281.

Levesque, R. J. R. (2007a). Reporting empirical research on adolescence: reflections on the appeal of coherence, purpose and responsibility. Journal of Youth and Adolescence, 36, 1-9.

Levesque, R. J. R. (2007b). Reflections on a legendary contribution to the empirical study of adolescence. Journal of Youth and Adolescence, 36, 1-4. 